\title{
Effect of Non-uniform Convection on Entropy Generation and Enthalpy for the Laminar Developing Pipe Flow of a High Prandtl Number Fluid
}

\author{
Reza Kakulvand \\ Department of Chemical Engineering, University of Sistan and Baluchestan, Zahedan, Iran \\ Email address: \\ Rezakakulvand93@gmail.com \\ To cite this article: \\ Reza Kakulvand. Effect of Non-uniform Convection on Entropy Generation and Enthalpy for the Laminar Developing Pipe Flow of a High \\ Prandtl Number Fluid. World Journal of Applied Chemistry. Vol. 4, No. 4, 2019, pp. 69-78. doi: 10.11648/j.wjac.20190404.15
}

Received: September 1, 2019; Accepted: September 29, 2019; Published: November 19, 2019

\begin{abstract}
In a boundary wall of a pipe for developed laminar flow, to find the best example in which the least enthalpy and entropy are created, non-uniform distribution of convective flow in wall is studied. Some factors are simulated for transfer coefficient heat variations of moving the pipe. Distribution of temperature, entropy and enthalpy along the radius and distribution of generated entropy and enthalpy along the tube axis are shown. Entropy and enthalpy are reduced along the axis. Entropy, except some areas close to the wall, is increasing along the radius. Temperature and enthalpy, approaching the wall along the radius, have increased.
\end{abstract}

Keywords: Generated Entropy, Enthalpy, Computational Fluid Dynamics

\section{Introduction}

Pipes are integral parts of industry. In different environments, various effects on the fluids within the pipe were exerted. Heat transfer coefficient and so, the special rate of entropy and enthalpy were entered to each of these environments. These variations are applied under various heat transfer conditions and different values. Enthalpy and entropy changes for various samples and tubes are investigated. Since Prandtl number of fluid is high, the high amount of heat in the boundary layer is put on pipes. Correlation, momentum and energy equations, as well as first and second laws of thermodynamics in the boundary layer of pipes were studied by Bejan [1]. A variety of properties such as design, construction, repair and maintenance are reported by Antaki, et. al. [2]. Enthalpy and energy balance of mechanical pipes in different situations, through the first law of thermodynamics was presented by Morrison. Entropy generation minimization (EGM) is a method resulted in availability for optimization that is reported by bejan and Cheng Xue-Tao [4, 5]. Entropy generation minimization (EGM) of pipes for optimization is investigated by Gheorghian et al. [6]. Heat transfer coefficient of movement depends on various factors such as environmental Changes, fluid, temperature and surface contact [7] Effect of non-uniform temperature distribution on entropy generation and enthalpy for the laminar developing pipe flow of a high Prandtl number fluid is investigated by Reza kakulvand [9]. The effects of transient heat flux on the tube in contact with the natural convection, on enthalpy and entropy generation, for developed laminar flow of fluid with high Prandtl number is shown Reza kakulvand [10]. The effects of transient radiant flow on pipe in contact with natural convection, for developed laminar flow of fluid with high Prandtl number, on enthalpy and entropy production by Reza kakulvand is obtained [11]. Investigation of drag coefficients in gas - liquid tower and boundary conditions on pipes is presented by Rezakakulvand [12]. Convective heat transfer of molten salt in tubes copper-coated has been employed by shen et al [19] The effects of entropy generation during the turbulent convective heat transfer, for tubes with different characteristics, have been exhibited by Mohseni, et al [14] Numerical and experimental studies in solar thermal absorber tubes with non-uniform heat transfer have been studied by chang, et al [15]. Convection heat transfer for a fixed heat flux has been assayed by Mohammed, et al [13] Convection in simulation in order to study the effect of condenser tube dip, has been utilized by Minocha, et al [16]. Convective heat transfer at the supercritical pressure, on the fluids, has been 
reviewed by Huange, et al [19]. Minimum entropy generation in the boundary layer as well as convection has been demonstrated by Bejan et al and Jiji et al [17, 25]. Entropy generation and energy conversion rates in a tube have been represented by Akbar, et al [20]. Entropy generation of mixed convection has been studied by Wang, et al [21]. Entropy generation of convection has been investigated by Chen, et al [24]. Mixed convection in a cylinder has been tested by Elsherbiny, et al [22]. The effects of natural convection of channel have been studied by $\mathrm{Heo}$, et al [23]. Some experimental and numerical methods to obtain natural convective heat transfer have been suggested [18, 19, 23, 24].

$\mathrm{h}$

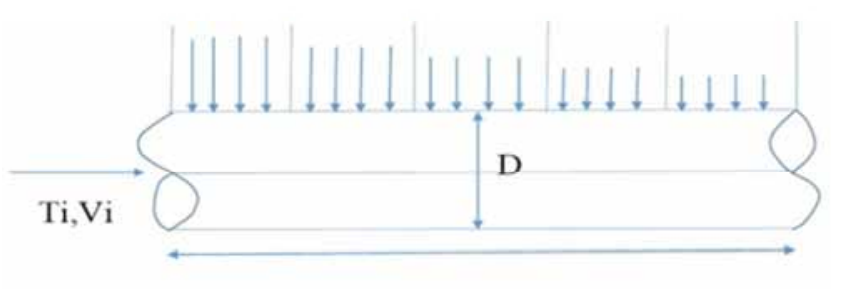

L

Figure 1. Schematic of pip in non-uniform convection.

In this article, developed laminar flow of pipes, along with non-uniform convection flow on the wall, are studied for several samples. For each sample, temperature distribution along the radius, enthalpy and generated entropy along the radius and axis are illustrated by some diagrams. The impacts of various values for convection flow to each other due to distribution of transfer coefficient values of movement in a small-scale one-meter pipe have been studied. The optimized condition for enthalpy and generated entropy is assayed. Entropy and enthalpy generation minimization lead to increase economic efficiency in industry.

\section{Physical Model}

Laminar flow regime, steady-state conditions, incompressible fluid and high Prandtl numbers, in symmetry of the pipe, has been investigated. The Non-uniform convection heat transfer on heating tube surface is shown in Figure 1 . The pipe geometry with a length of $1 \mathrm{~m}$ and diameter $0.025 \mathrm{~m}$ in five parts was designed. Convection flow changes in five pipe sections and seven samples have been investigated. Chart speed along the pipe is fixed, because fluid velocity is constant. The temperature graph is variable because convection flow changes on the tube surface are applied.

Fluid properties and pipe geometry specifications are indicated in Table 1.

Table 1. Fluid properties and pipe geometry specifications.

\begin{tabular}{lll}
\hline Fluid properties & Variable & value \\
\hline Specific heat transfer at constant pressure & $C_{p}(j / k g k)$ & 1845 \\
Thermal conductivity & $k(w / m k)$ & 0.146 \\
\hline
\end{tabular}

\begin{tabular}{lll}
\hline Fluid properties & Variable & value \\
\hline Density & $\rho\left(\mathrm{kg} / \mathrm{m}^{3}\right)$ & 889 \\
Viscosity (at $\left.T_{\text {ref }}\right)$ & $\mu\left(\mathrm{NS} / \mathrm{m}^{2}\right)$ & 1.06 \\
Prandtl number, pr & & 13400 \\
Inlet axial fluid velocity & $V_{i}(\mathrm{~m} / \mathrm{s})$ & 0.02 \\
Inlet fluid temperature $T_{i}(k)$ & & 273.15 \\
Reference temperature, $\mathrm{T}_{\text {ref }}(\mathrm{k})$ & & 288.16 \\
geometry of pipe & & \\
Pipe length & $\mathrm{D}(\mathrm{m})$ & 0.025 \\
Pipe diameter & $\mathrm{L}(\mathrm{m})$ & 1 \\
\hline
\end{tabular}

\section{The Governing Equations}

The governing equations in two-dimensional coordinates of pipe, in Bejan's heat transfer are as follows:

Continuity equations:

$$
\frac{\partial v_{r}}{\partial r}+\frac{v_{r}}{r}+\frac{\partial v_{z}}{\partial z}=0
$$

Momentum equations:

$$
\begin{gathered}
\rho\left(v_{r} \frac{\partial v_{r}}{\partial r}+v_{z} \frac{\partial v_{r}}{\partial z}\right)=-\frac{\partial P}{\partial r}+\mu\left\{\frac{\partial}{\partial r}\left[\frac{1}{r} \frac{\partial}{\partial r}\left(r v_{r}\right)+\frac{\partial^{2} v_{r}}{\partial z^{2}}\right]\right\} \\
\rho\left(v_{r} \frac{\partial v_{r}}{\partial r}+v_{z} \frac{\partial v_{z}}{\partial z}\right)=-\frac{\partial P}{\partial z}+\mu\left\{\frac{1}{r} \frac{\partial}{\partial r}\left[r \frac{\partial v_{z}}{\partial r}\right]+\frac{\partial^{2} v_{z}}{\partial z^{2}}\right\}
\end{gathered}
$$

Energy equations:

$$
\rho C_{p}\left(v_{r} \frac{\partial T}{\partial r}+v_{z} \frac{\partial T}{\partial z}\right)=k\left\{\frac{1}{r} \frac{\partial}{\partial r}\left[r \frac{\partial T}{\partial r}\right]+\frac{\partial^{2} T}{\partial z^{2}}\right\}+\mu \phi
$$

Where:

$$
\phi=2\left[\left(\frac{\partial v_{r}}{\partial r}\right)^{2}+\left(\frac{v_{r}}{r}\right)^{2}+\left(\frac{\partial v_{r}}{\partial r}\right)^{2}\right]+\left(\frac{\partial v_{r}}{\partial z}+\frac{\partial v_{z}}{\partial r}\right)^{2}
$$

\section{Enthalpy and entropy}

Non-slip conditions defined within the wall and the symmetry in central line. Generated entropy includes viscous part, temperature changes along the radius and wall depending on thermal conductivity. Viscous part is created by environs layers movement on each other. The relation is provided in two-dimensional coordinates.

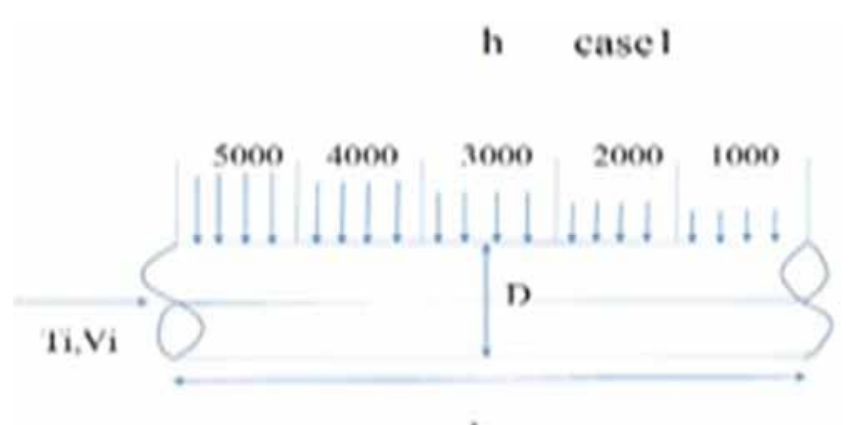


h case2

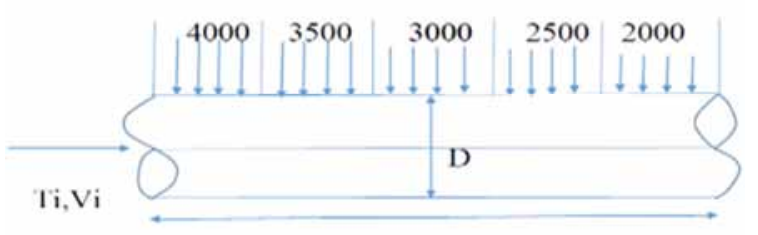

L

h case 3

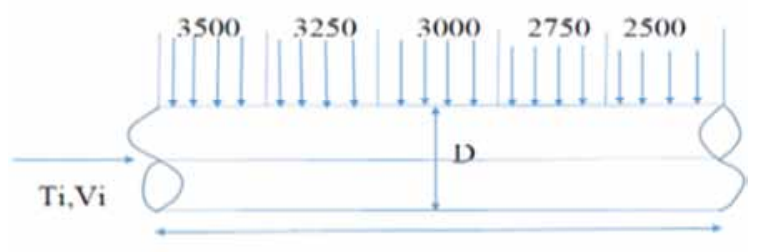

L

h case 4

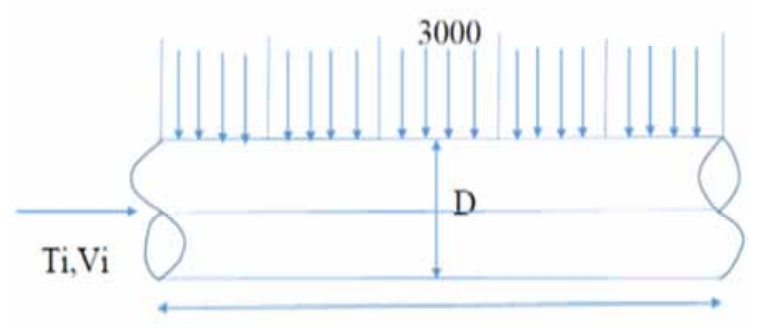

$\mathrm{L}$

h Case 5

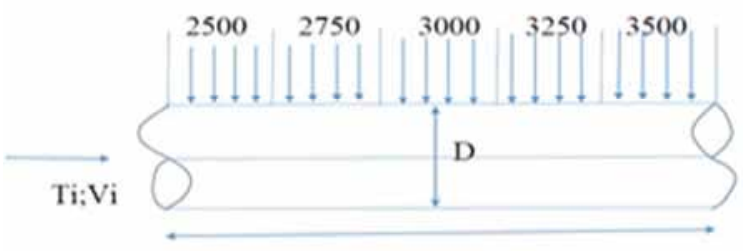

L.

h case6

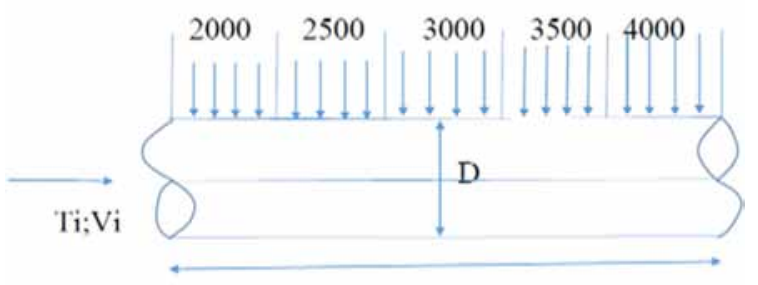

$\mathrm{L}$

Figure 2. Diagram of 7 cases of pip in non-uniform convection.

\section{Problem Definition}

The aim of this article is to find distribution of heat transfer coefficient of movement exerting in the pipe followed by enthalpy and entropy generation minimization. Distribution of convective heat transfer is put on the pipe surface. A variety of values for generated enthalpy and entropy for various samples have been found depending on convective flow amount. Average value of heat transfer coefficient for total movement of 7 samples in 4 th sample equals to $5000 \mathrm{w} / \mathrm{km}^{2}$. The effects of heat transfer coefficient of pipe movement, temperature distribution along the radius, and generated enthalpy and entropy along radius and axis in different charts have been simulated by computational fluid dynamics.

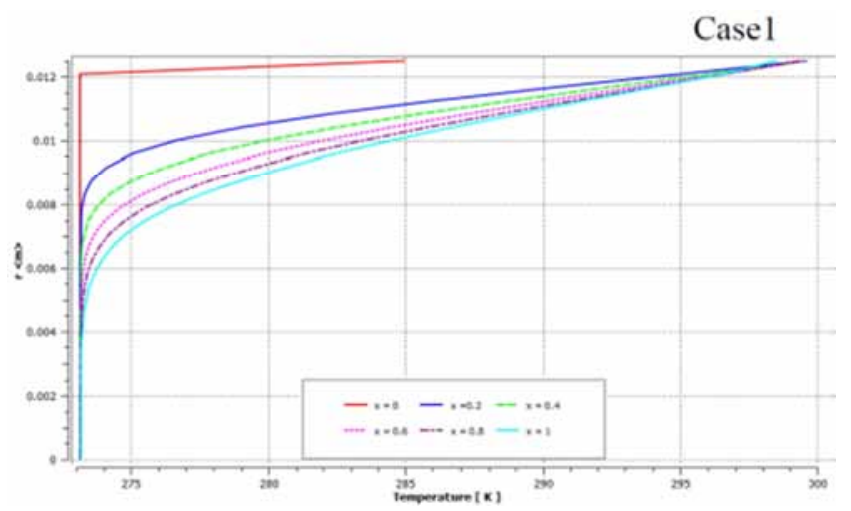

case 2

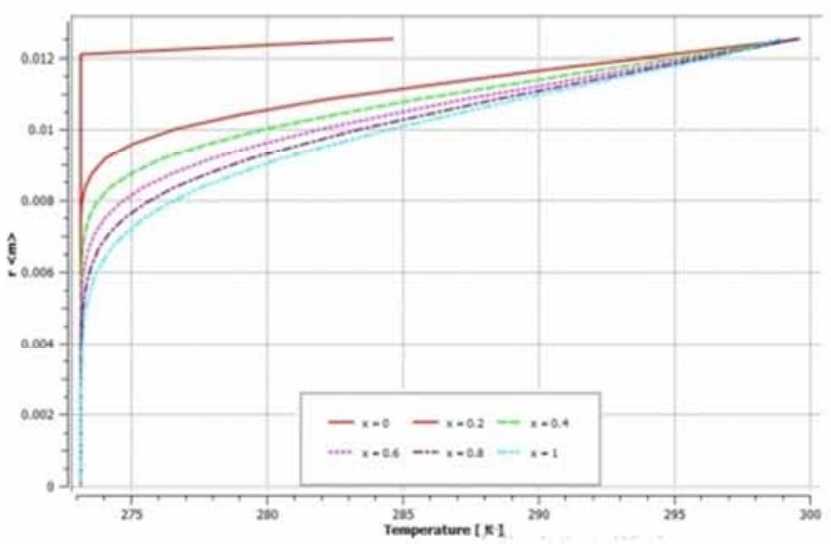

case 3

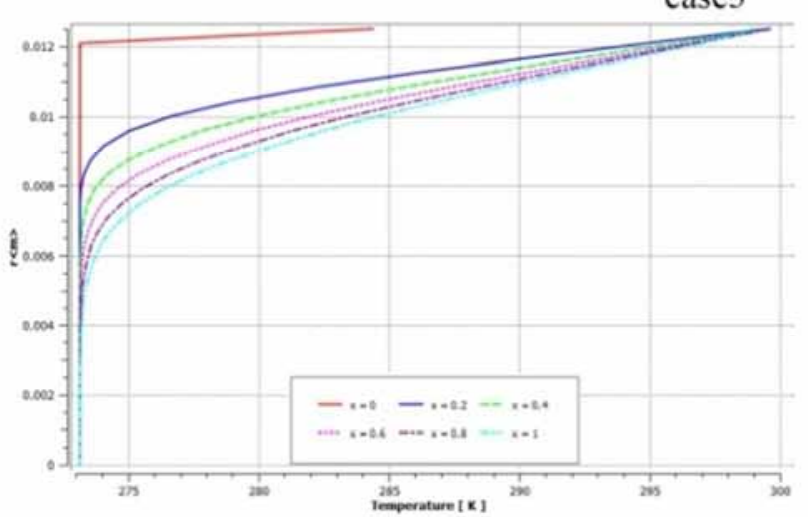



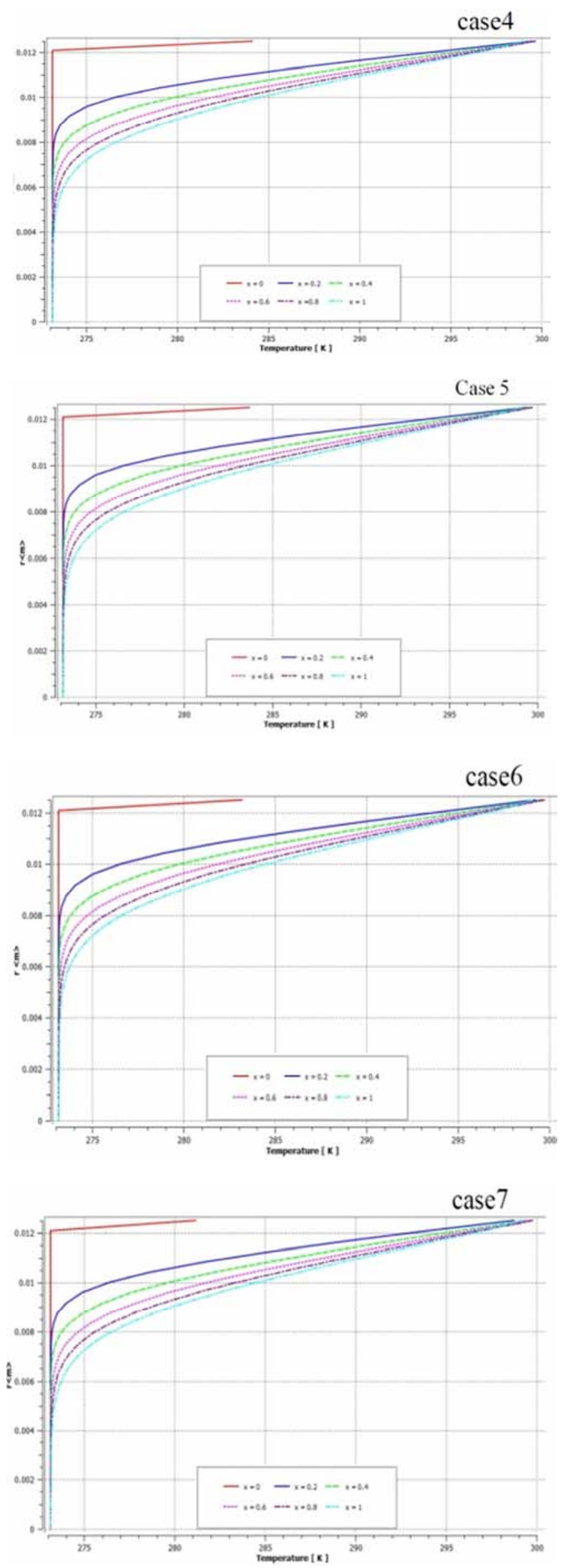

Figure 3. Temperature distribution along the radius.
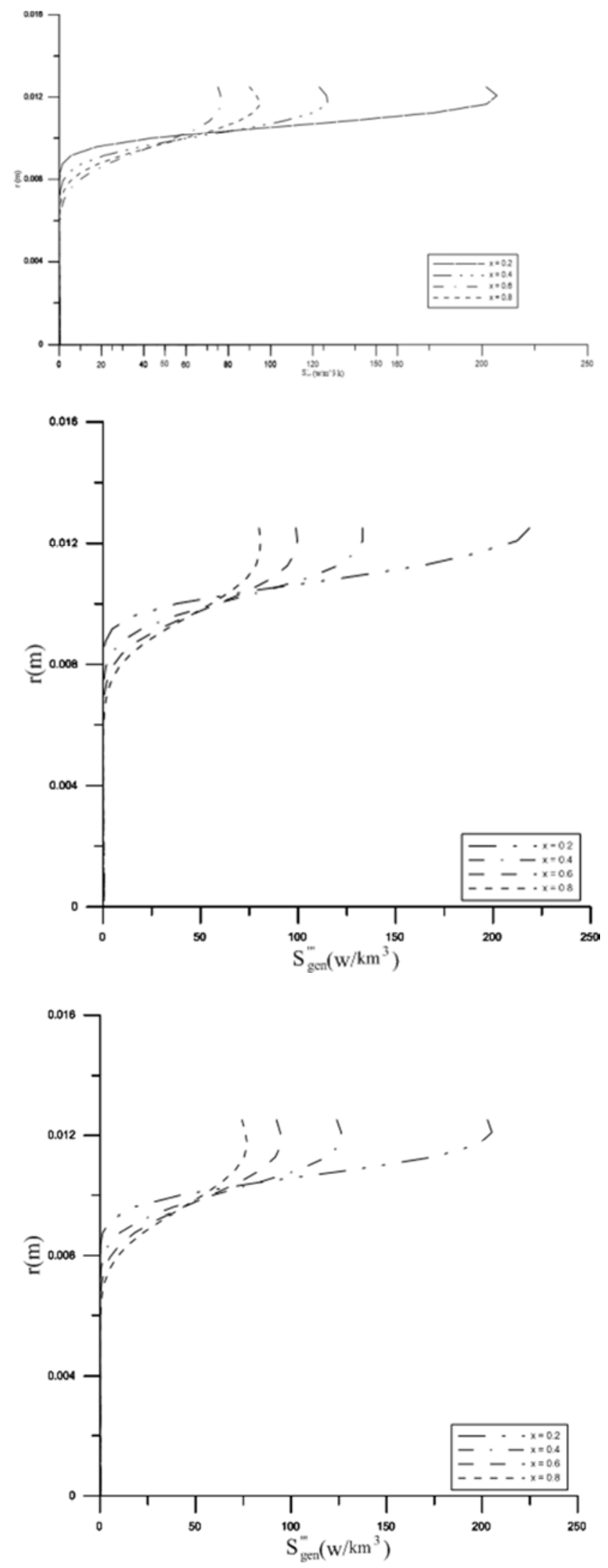

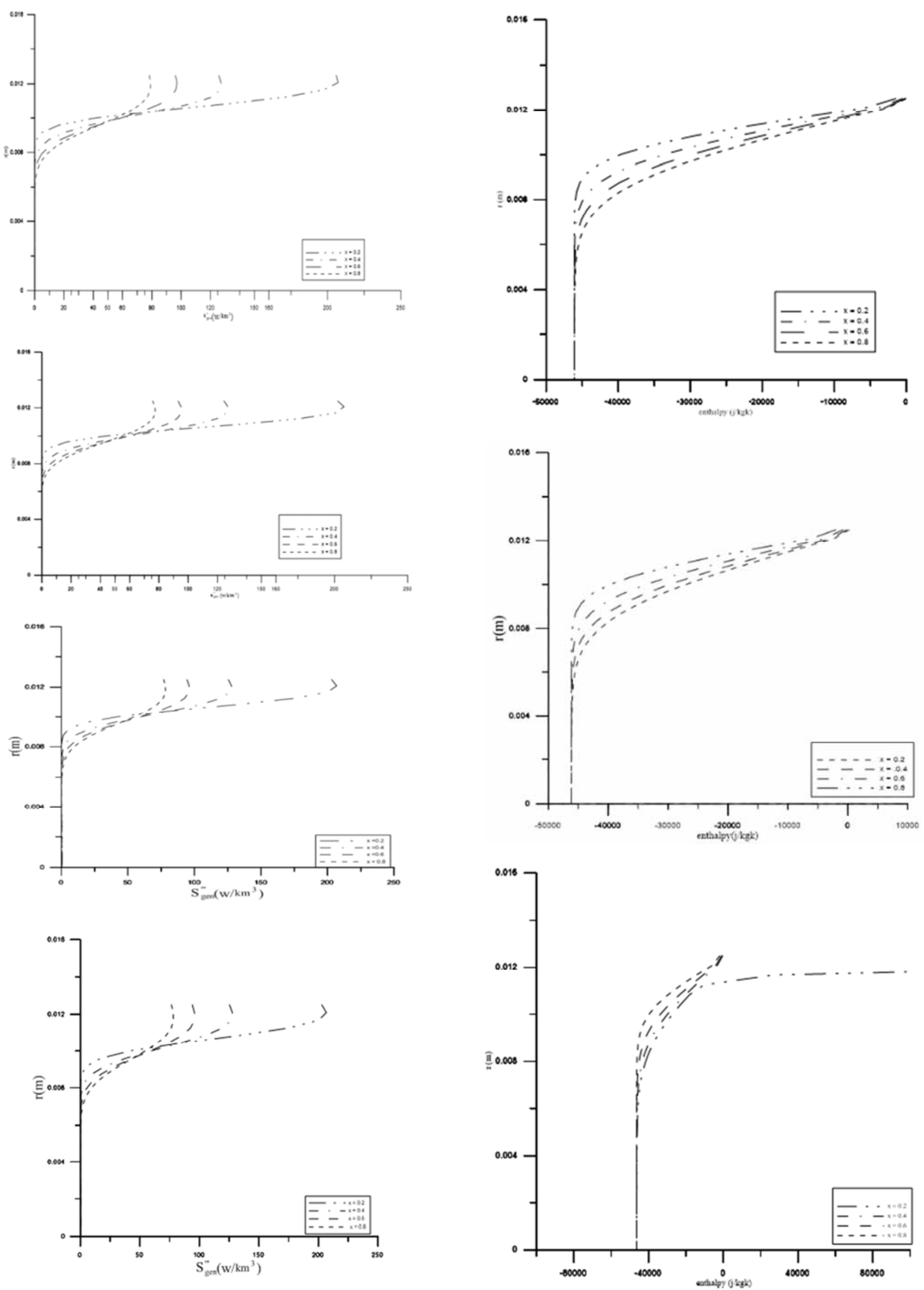

Figure 4. Entropy generation along the radius. 

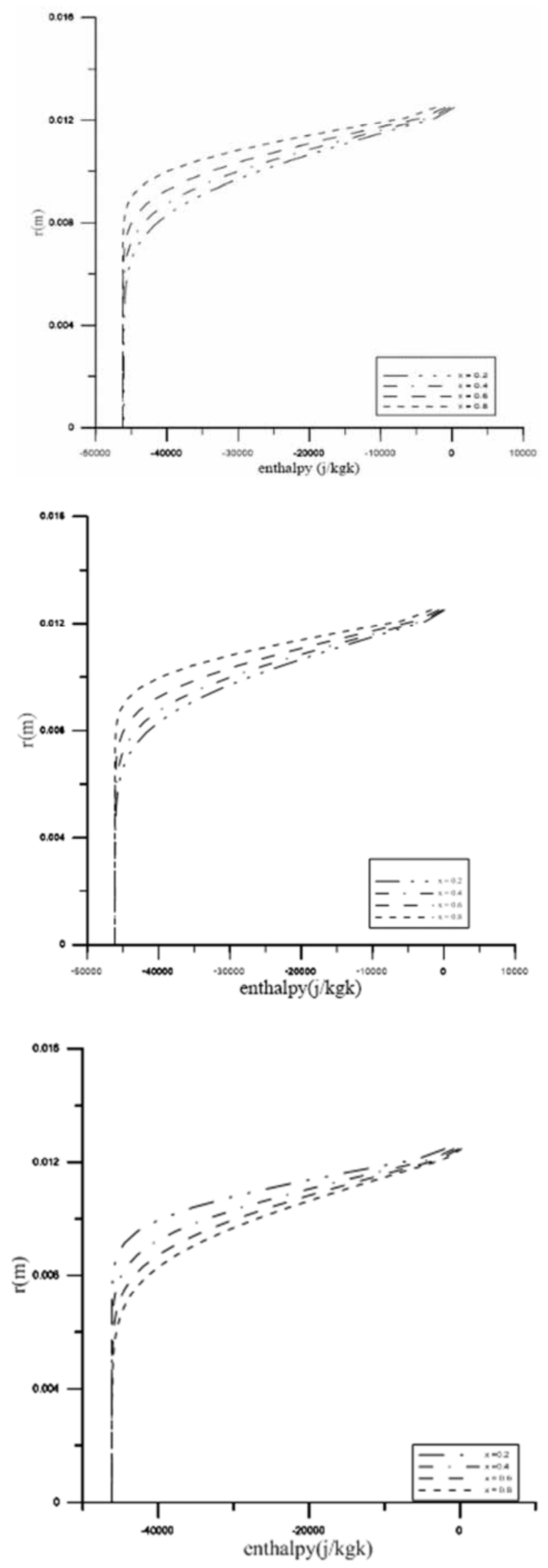

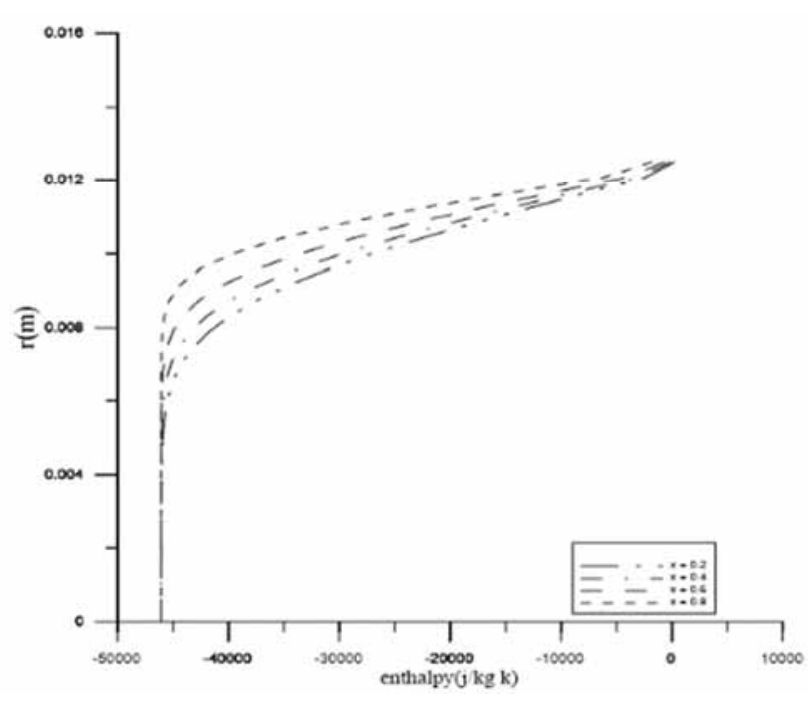

Figure 5. Enthalpy along radius.
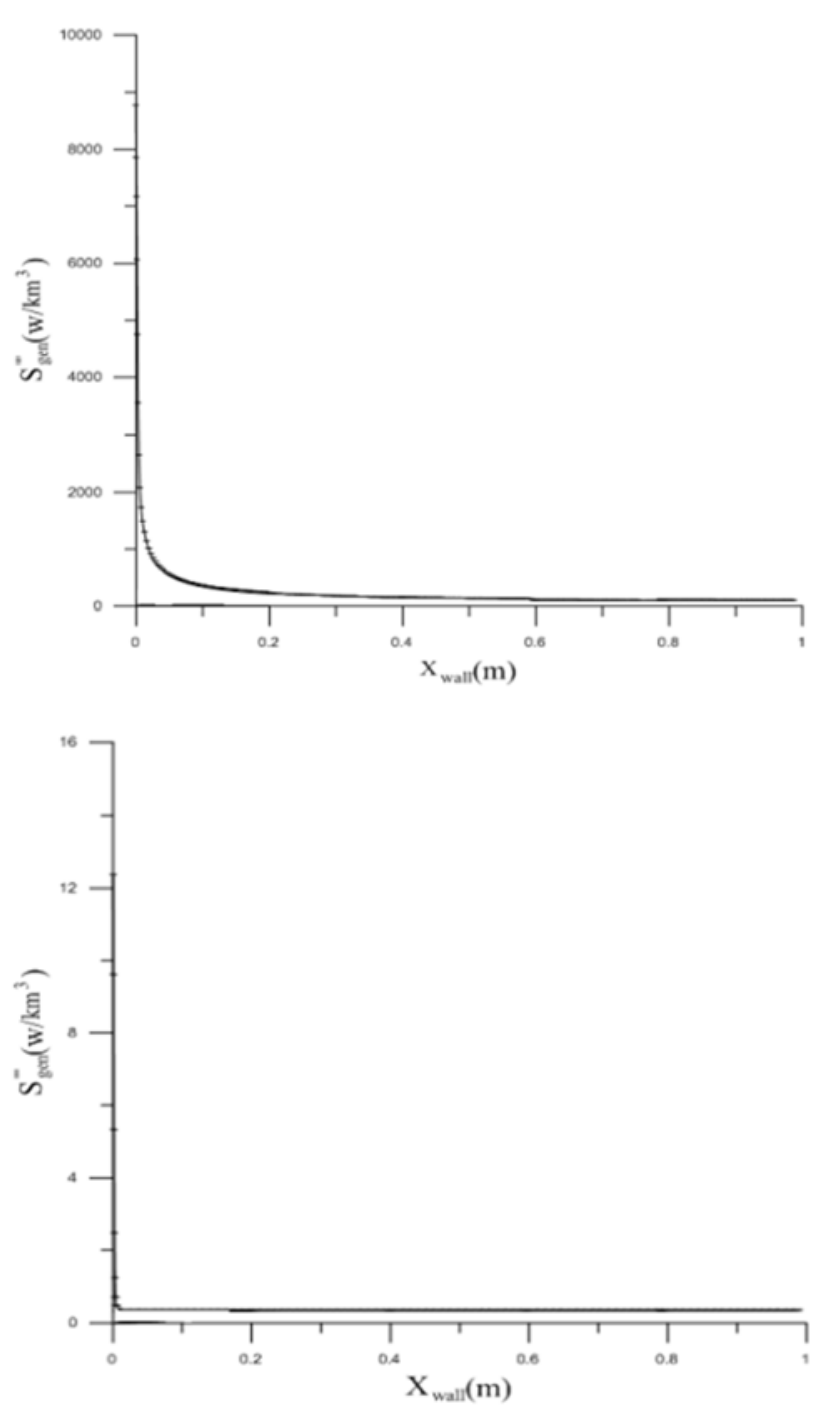

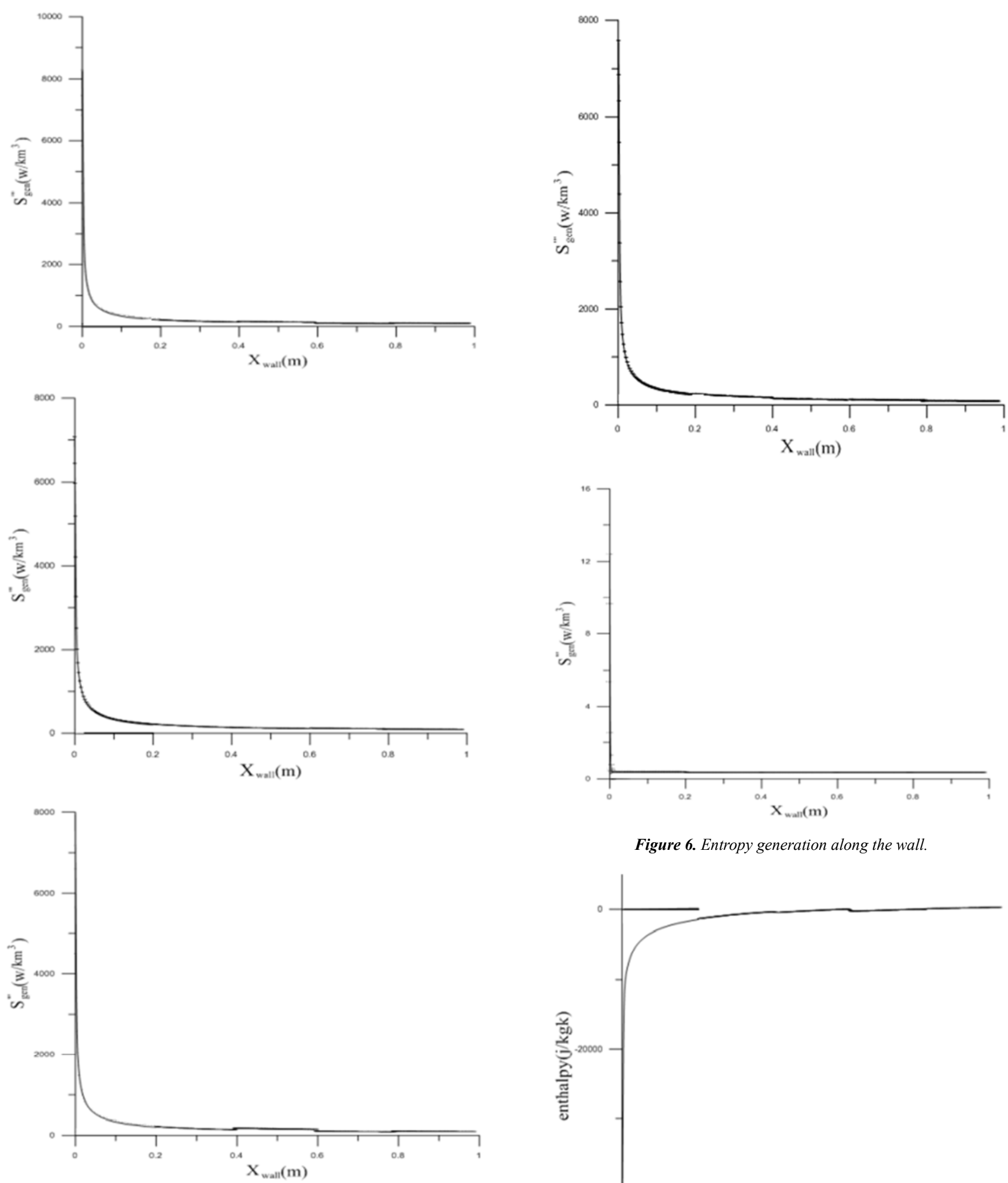

Figure 6. Entropy generation along the wall.

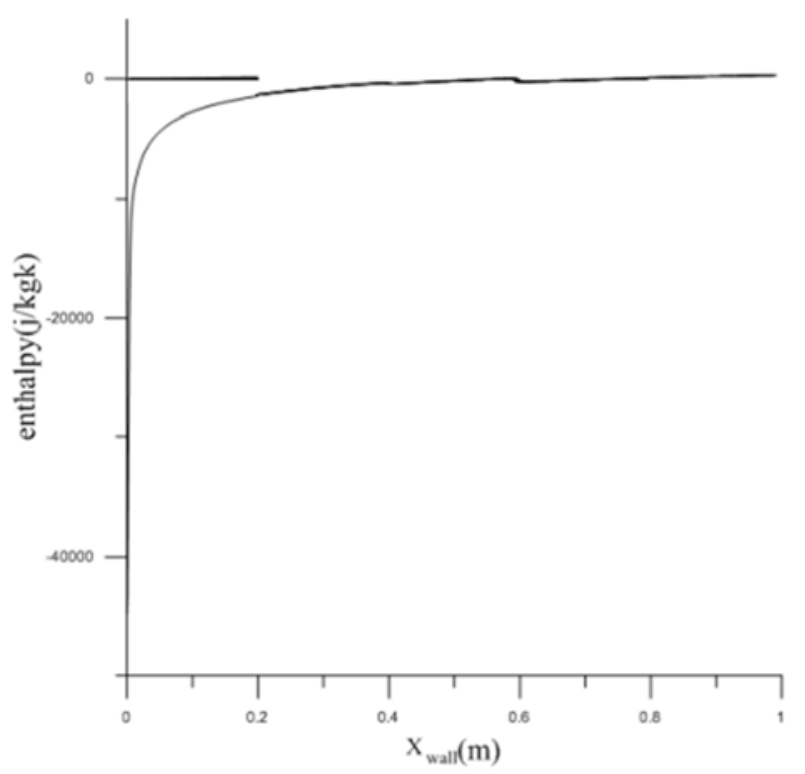



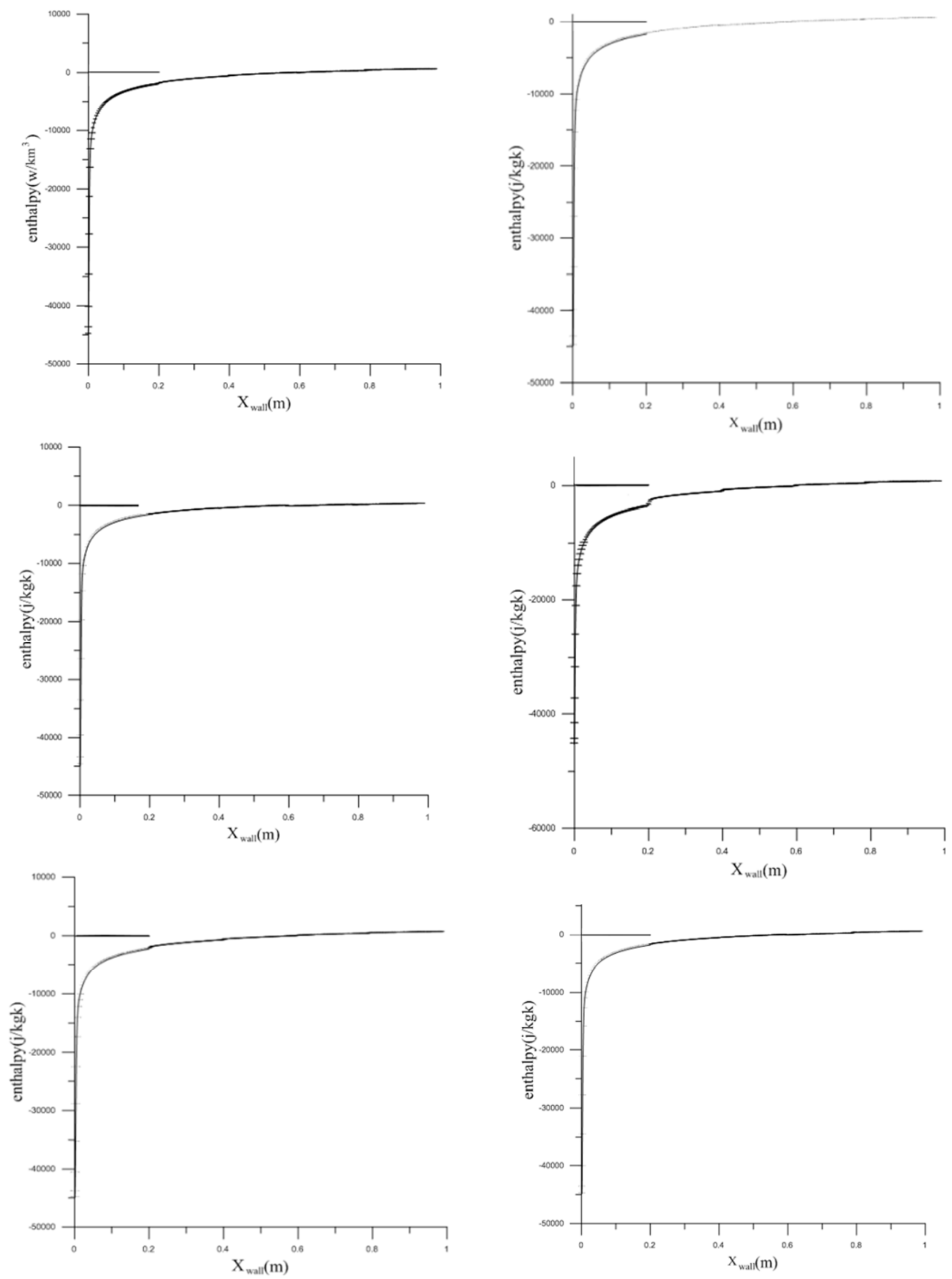

Figure 7. Enthalpy along the wall. 


\section{Results and Discussion}

Entering the liquid into the pipe, the heat enters to cylinder. Imported Heat is investigated from different directions.

In the $3^{\text {rd }}$ chart, distribution of temperature along the radius is shown. Temperature is fixed in pipe center and in boundary layer near to the wall, variations are increased. Approaching the wall, to a certain distance, the temperature in the pipe is fixed and flow lines have constant temperature. With the passage of this distance and approaching to the wall, temperature in terminal points is higher than preliminary points along the axis. Their amounts for in different lengths along the axis have been shown. The trend for heat transfer distribution of various movements is similarly performed.

In the chart 4 , the generated entropy of convective flow along the radius is obtained. Most of these changes have been applied in the boundary layer near the wall. Like temperature, the amount of entropy generation to a distance of radius near the wall of the pipe is constant. Passing this distance, for charts, Two concavity in different directions, for generated entropy, in line with radius, is achieved. In a special area of the radius, the amount of Entropy along the pipe is approximately constant. In this range, concavity direction of chart is changed. The range of entropy variations at the beginning of the end of the pipe is more than the end.

In the chart 5, the amount of enthalpy along the pipe radius has been shown. Approaching to pipe wall, enthalpy increases. The amount of this enthalpy, for a certain radius near the wall, at the beginning of pipe is more than the end.

In chart 6 , the amount of generated entropy along the wall is given. The entropy at the beginning of pipe is maximum and increasing the axis length at the beginning of tube leads to decrease suddenly and decreasing trend is continued along the pipe. In the end of pipe, the generated entropy is constant.

In the Figure 7, the amount of enthalpy along the pipe is increasing. Ascending trend has strongly been accelerated at the beginning of pipe. Uptrend increases with increasing the length of wall and in the end parts of the pipe and its maximum, the amount is almost constant.

For the pipes and channel passing through different fluids, each of fluids has a special heat transmission coefficient. Mohammed, H. A. and Y. K. Salman, Free convective heat transfer from a constant heat flux vertical circular tube with different entrance restrictions length. Energy Conversion and Management, 2007. 48 (7): p. 2233-2243. Passing pipe or channel across different fluids, distribution of heat transfer coefficient of movement is created in pipe or channel pipe. For the fluid transfer pipes also, passing different convective environment, the results are useful to reach enthalpy and entropy generation minimization.

The results of this work are applicable in tubes that are in contact with convection and various fluids and air in convective heat transfer in environments with natural or forced convection the electric coil is wrapped on the tube as heat flux, the implications of this paper is used. Electric and diesel furnace, solar water heaters, refrigerant tube are the applications of convection distribution tubes.

\section{References}

[1] A Bejan, Convection Heat Transfer, 3rd ed, New York, John Wiley \& Sons; 2004, pp 1-24.

[2] G. A. Antaki, Piping and Pipeline Engineering, New York, Basel Marcel Dekker, 2003.

[3] F A. Morrison," Mechanical Energy Balance: Intro and Overview", Michigan, 9June, 2005.

[4] A Bejan, "Entropy generation minimization: The new thermodynamics of finite-size devices and finite-time processes", Applied Physics Reviews, Vol. 79, No. 3, 1 February 1996.

[5] C Xue-Tao. L Xin-Gang, "Applicability of the minimum entropy generation methodfor optimizing thermodynamic cycles", Chin. Phys. B Vol. 22, No. 1. 2013.

[6] A. Gheorghlan, A. Dobrovicescu, A. Marin, C. IONIȚĂ,"Termodynamic optimization of Tubular Heat Exchangers based on minimum. Irreversibility Critera, Bucharest, 2013.

[7] F. P. Incropera, D P Dewitt, Introduction to Heat Transfer, fourth ed, 2002.

[8] J. A. Esfahani, P. B. Shahabi, Effect of "non-uniform heating on entropy generation for the laminar developing pipe flow of a high Prandtl number fluid", Energy Conversion and Management 51, 27 February 2010.

[9] R. kakulvand, "Effect of non-uniform temperature distribution on entropy generation and enthalpy for the laminar developing pipe flow of a high Prandtl number fluid", chemical review and latter, 23 August, 2019.

[10] R. kakulvand, "The effects of transient heat flux on the tube in contact with the natural convection, on enthalpy and entropy generation, for developed laminar flow of fluid with high Prandtl number", Persian journal of miiad andishe, February, 2018.

[11] R. kakulvand, "Effect of non-uniform convection distribution on entropy generation and enthalpy for the laminar developing pipe flow of a high Prandtl number fluid", Persian journal of miiad andishe, February, 2018.

[12] R. kakulvand, "Investigation of drag coefficients in gas liquid tower and boundary conditions on pipes", Persian journal of miiad andishe, February, 2018.

[13] Mohammed, H. A. and Y. K. Salman, Free convective heat transfer from a constant heat flux vertical circular tube with different entrance restrictions length. Energy Conversion and Management, 2007. 48 (7): p. 2233-2243.

[14] Mohseni, M. and M. Bazargan, Entropy generation in turbulent mixed convection heat transfer to highly variable property pipe flow of supercritical fluids. Energy Conversion and Management, 2014. 87: p. 552-558.

[15] Chang, C., X. Li, and Q. Q. Zhang, Experimental and Numerical Study of the Heat Transfer Characteristics in Solar Thermal Absorber Tubes with Circumferentially Non-uniform Heat Flux. Energy Procedia, 2014. 49: p. 305-313.

[16] Minocha, N., et al., 3D CFD simulations to study the effect of inclination of condenser tube on natural convection and thermal stratification in a passive decay heat removal system. Nuclear Engineering and Design, 2016. 305: p. 582-603. 
[17] Bejan, A., The Method of Entropy Generation Minimization, in Energy and the Environment, A. Bejan, P. Vadász, and D. G. Kröger, Editors. 1999, Springer Netherlands: Dordrecht. p. $11-22$.

[18] Jha, B. K. and M. O. Oni, Natural convection flow in a vertical tube inspired by time-periodic heating. Alexandria Engineering Journal, 2016. 55 (4): p. 3145-3151.

[19] Huang, D., et al., A brief review on convection heat transfer of fluids at supercritical pressures in tubes and the recent progress. Applied Energy, 2016. 162: p. 494-505.

[20] Akbar, N. S., Entropy generation and energy conversion rate for the peristaltic flow in a tube with magnetic field. Energy, 2015. 82: p. 23-30.

[21] Wang, T., Z. Huang, and G. Xi, Entropy generation for mixed convection in a square cavity containing a rotating circular cylinder using a local radial basis function method.
International Journal of Heat and Mass Transfer, 2017. 106: p. 1063-1073.

[22] Elsherbiny, S. M., M. A. Teamah, and A. R. Moussa, Experimental mixed convection heat transfer from an isothermal horizontal square cylinder. Experimental Thermal and Fluid Science, 2017. 82: p. 459-471.

[23] Heo, J. -H. and B. -J. Chung, Influence of helical tube dimensions on open channel natural convection heat transfer. International Journal of Heat and Mass Transfer, 2012. 55 (11-12): p. 2829-2834.

[24] Chen, H. -T., et al., Numerical and experimental study of natural convection heat transfer characteristics for vertical plate fin and tube heat exchangers with various tube diameters. International Journal of Heat and Mass Transfer, 2016. 100: p. 320-331.

[25] Jiji, L., M. Heat Convection, New York, 2006. 